\title{
APLIKASI POLLING DAN INFORMASI DENGAN SMS GATEWAY
}

\author{
Labib Muhajir ${ }^{1)}$ Muhyiddin Zainul Arifin ${ }^{2)}$ Tholib Hariono ${ }^{3)}$ \\ 1) 2) e-mail : muhyiddin_arifin@yahoo.co.id \\ 3) e-mail : harionotholib@gmail.com
}

\begin{abstract}
Information and poll are important things in organization. Which with information organization can be coordinated. While poll is a democration in organitation. Application For Poll and Information is build to help those needs.

Application For Poll and Information is based on literature and observations on existing polling system. Application For Poll and Information is SMS Gateway application with Visual FoxPro 9.0 programming language and Gammu. Application For Poll and Information is running on a computer to receive information through SMS and process the data into criticism, suggestions. questions and polls.
\end{abstract}

Keywords: Poll, Information, SMS Gateway 


\section{Pendahuluan}

\subsection{Latar Belakang}

Organisasi merupakan wadah bagi orang-orang untuk berkumpul, bekerjasama secara rasional dan sistematis, terencana, terkendali dalam memanfaatkan sumber daya baik, sarana prasarana, data lainnya untuk digunakan secara efisien dan efektif untuk mencapai suatu tujuan.

Dalam menjalankan organisasi yang merupakan kumpulan orang tentu dibutuhkan komunikasi yang baik guna menstransferkan informasi yang tepat tujuan dan cepat yang mana dewasa ini kebutuhan ini sudah terpenuhi dengan banyak cara, baik melalui jaringan pribadi yaitu melalui SMS atau Messenger atau melalui sosial media yang kurang lebih memiliki fitur serupa. Pun demikian tidak semua informasi berupa informasi pemberitahuan, saran atau sejenisnya. Adapula yang dinamakan polling yang merupakan kumpulan pendapat yang juga dikategorikan sebagai informasi bahkan merupakan salah satu yang penting dalam organisasi yang tak terlepas dari pendapat orang banyak.

Dengan latar belakang di atas kehadiran sebuah aplikasi polling dirasa perlu dalam organisasi. Bersamaan dengan itu kemampuan penginformasian akan menambah guna dari aplikasi yang akan dibuat

\subsection{Metodologi Penelitian}

Metode penelitian yang dilakukan penulis dalam penelitian ini yaitu dengan menggunakan metode penelitian R \& D (Research and Development) sebagai berikut:

1) Studi Pustaka

Dalam penelitian ini, penulis melakukan studi pustaka untuk memperoleh data-data melalui buku dan internet.

2) Analisis

Melakukan penelitian dan analisa terhadap aplikasi yang dibangun dengan aplikasi serupa dengan kebutuhan penginformasian dan polling yang disesuaikan.

\section{Landasan Teori}

\subsection{Polling}

Polling adalah suatu penelitian (survei) dengan menanyakan kepada masyarakat mengenai pendapat suatu isu atau masalah tertentu. Secara metodologis, polling adalah suatu teknik untuk menyelidiki apa yang dipikirkan orang terhadap isu atau masalah yang muncul. Jadi polling adalah metode untuk mengetahui pendapat umum. (Eriyanto, 1999).

\subsection{SMS Gateway}

SMS Gateway adalah suatu sistem yang menjembatani antara handphone dengan sistem yang menjadi server dengan SMS sebagai informasinya. (Sunardi, 2009)

\subsection{Pustaka Rujukan}

Peneliti melakukan studi pustaka dengan mempelajari buku-buku yang berhubungan dengan pemrograman Visual Foxpro dan SMS Gateway. Adapun buku yang digunakan adalah:

1) Proyek Populer SMS Gateway (Sofyan Maulana)

2) Mudah Menyusun Program Aplikasi dengan Microsoft Visual Foxpro (Dadang Sudrajat) 


\section{Perancangan Sistem}

\subsection{Kebutuhan Perangkat}

Perangkat yang dibutuhkan dalam pengaplikasian aplikasi ini adalah sebagai berikut:

1) Perangkat Keras (Hardware)

PC dengan spesifikasi Prosesor Pentium, RAM 128 MB, Hard disk 32 GB, modem/ponsel, printer.

2) Perangkat Lunak (Software)

Windows XP, Visual Foxpro 9.0 Runtime, Gammu 1.28, MySQL Server, MySQL ODBC 32bit, PDF Reader.

\subsection{Kebutuhan Informasi}

Informasi yang dibutuhkan oleh aplikasi ini adalah:

1) SMS Informasi

2) SMS Saran

3) SMS Polling

\subsection{Kebutuhan User}

Aplikasi ini dioperasikan oleh 2 user yaitu admin yang memiliki wewenang dalam mengolah aplikasi, user partisipan yang memanfaatkan fitur aplikasi ini melalui SMS.

\subsection{Perancangan Sistem}

\subsubsection{Diagram Use Case}

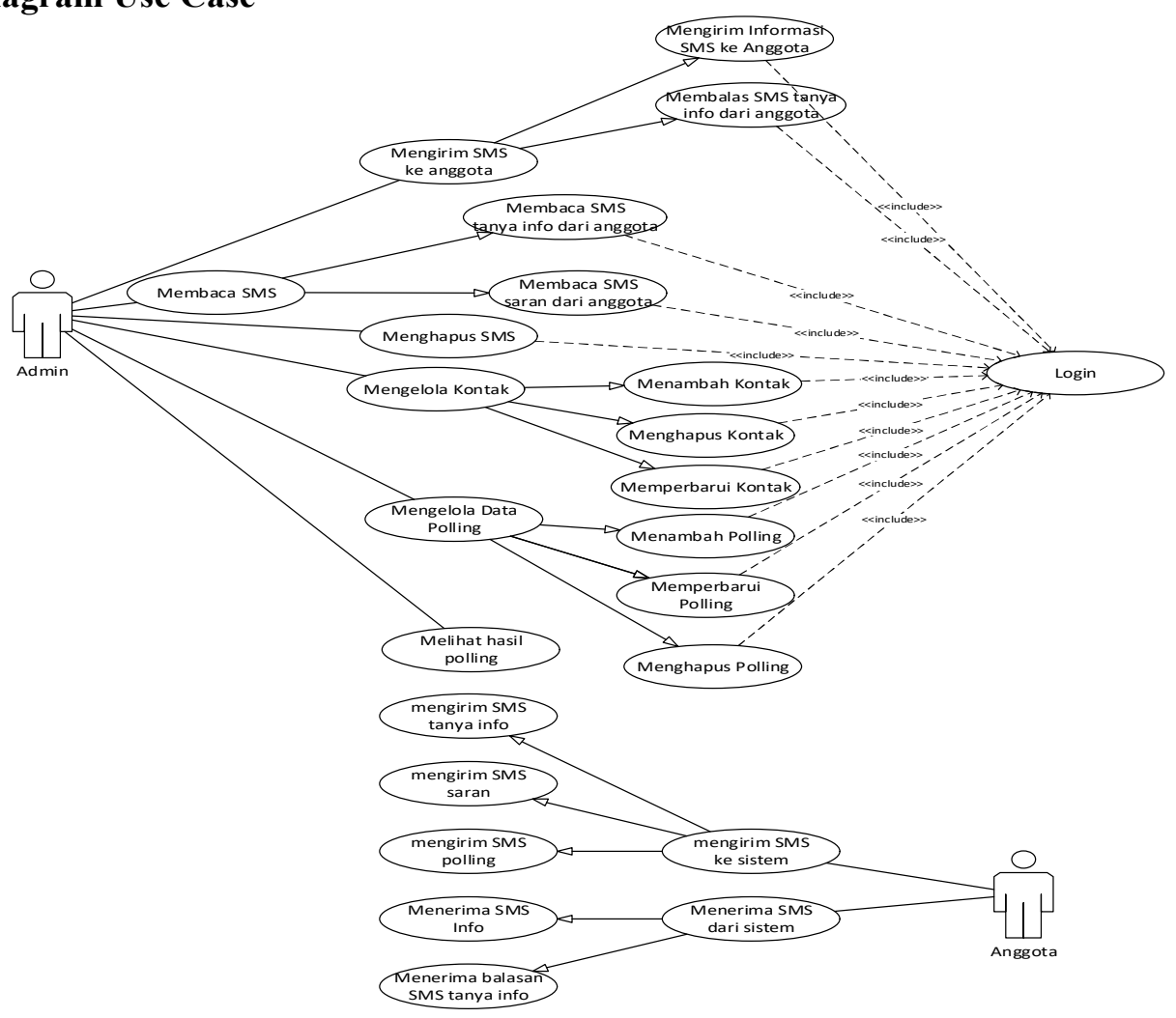

Gambar 3.1 Diagram Use Case Aplikasi Polling dan Informasi Dengan SMS Gateway 


\subsubsection{Data Flow Diagram}

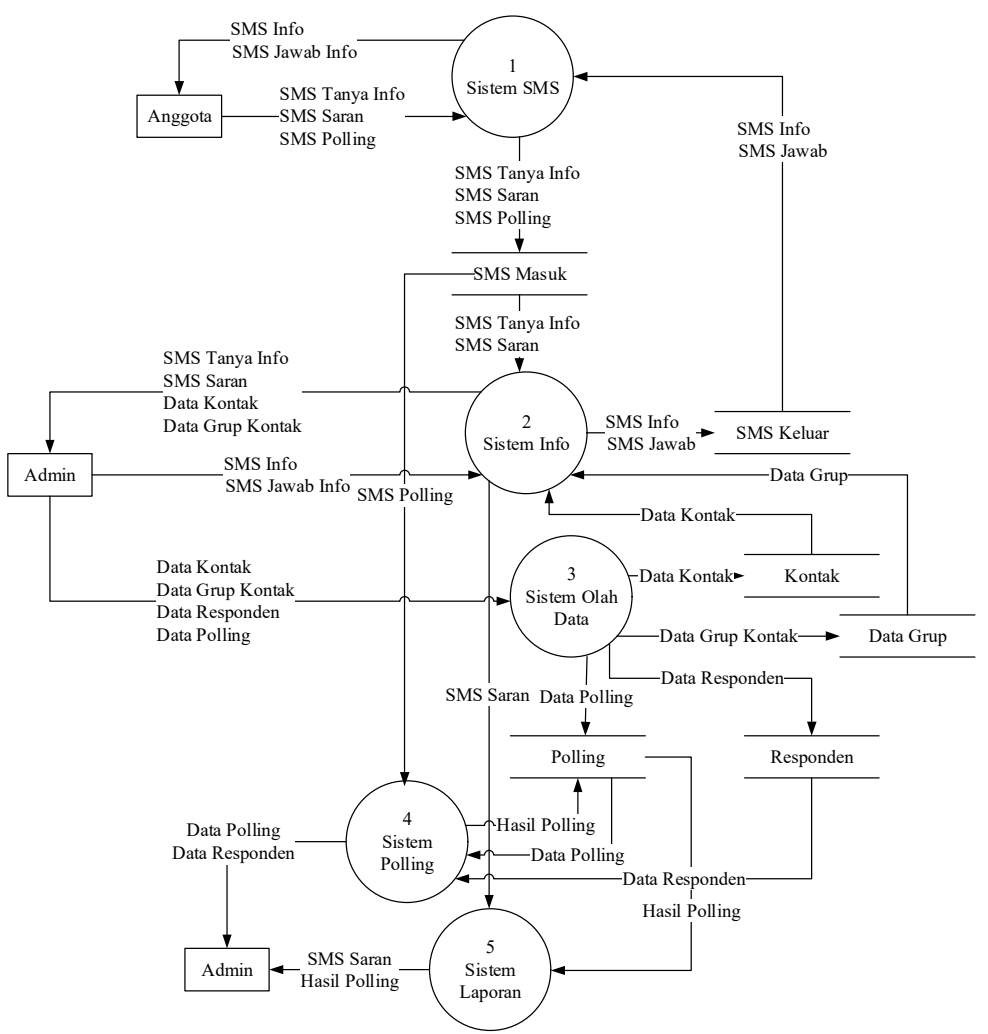

Gambar 3.2 Data flow diagram Aplikasi Polling dan Informasi Dengan SMS Gateway

\subsection{Perancangan Antarmuka}

Berikut adalah rancangan antarmuka Aplikasi Polling dan Informasi Dengan SMS Gateway:

1) Antarmuka Utama

\begin{tabular}{|l|}
\hline Aplikasi Polling dan Informasi Berbasis SMS \\
\hline Informasi Saran Polling Pengaturan Keluar \\
\hline \\
\end{tabular}

Gambar 3.3 Antarmuka utama 
2) Antarmuka Informasi

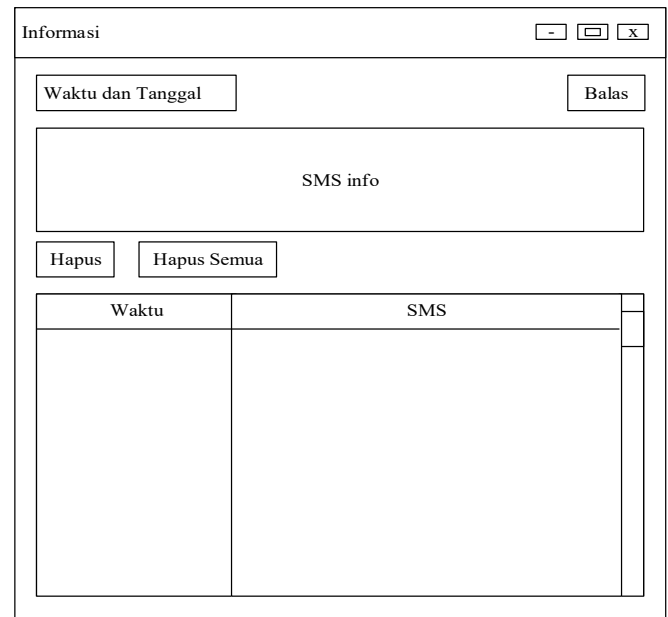

Gambar 3.4 Antarmuka informasi

3) Antarmuka Polling

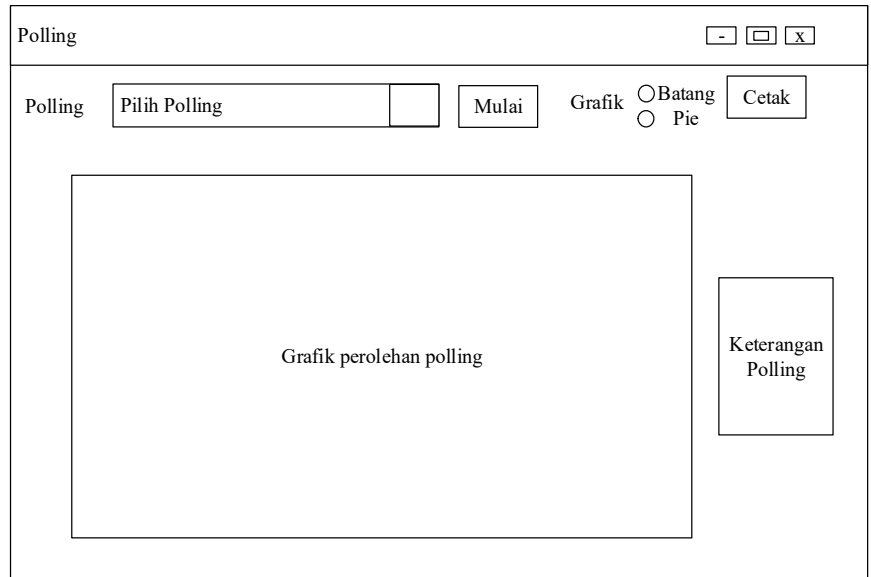

Gambar 3.5 Antarmuka polling

\section{Hasil dan Pembahasan}

\subsection{Hasil Interface Aplikasi}

Setelah dilakukan perancangan antarmuka maka didapati sebagian antarmuka yang dihasilkan adalah sebagai berikut:

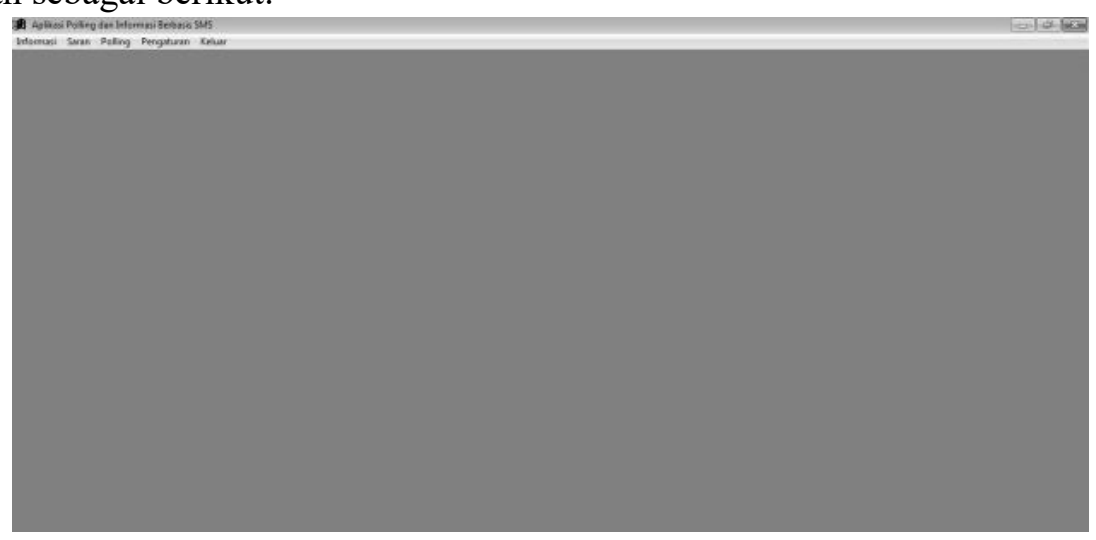

Gambar 4.1 Antamuka form utama 


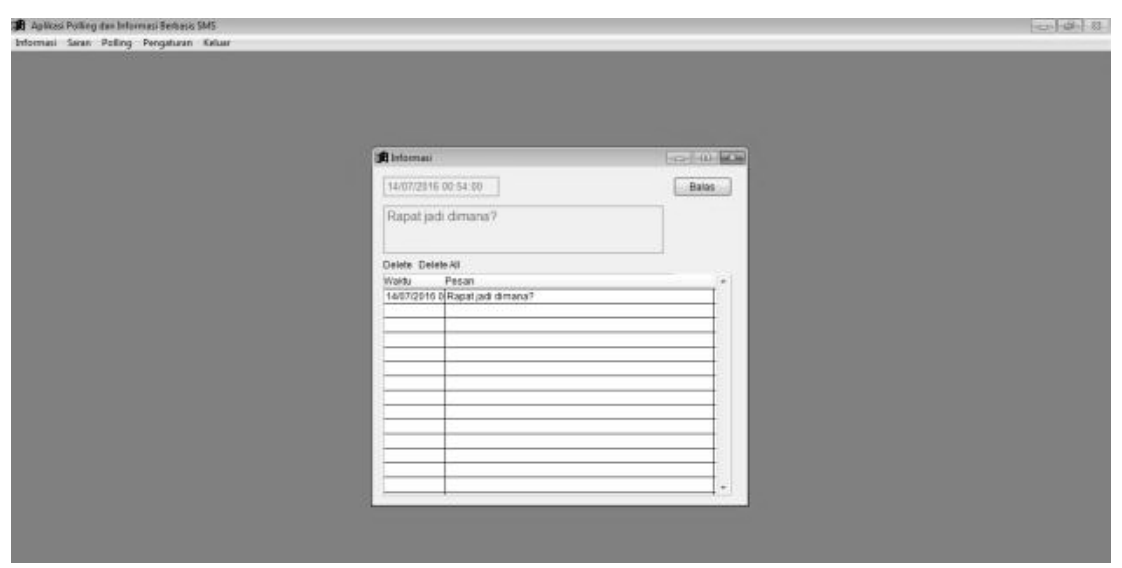

Gambar 4.2 Antarmuka form informasi

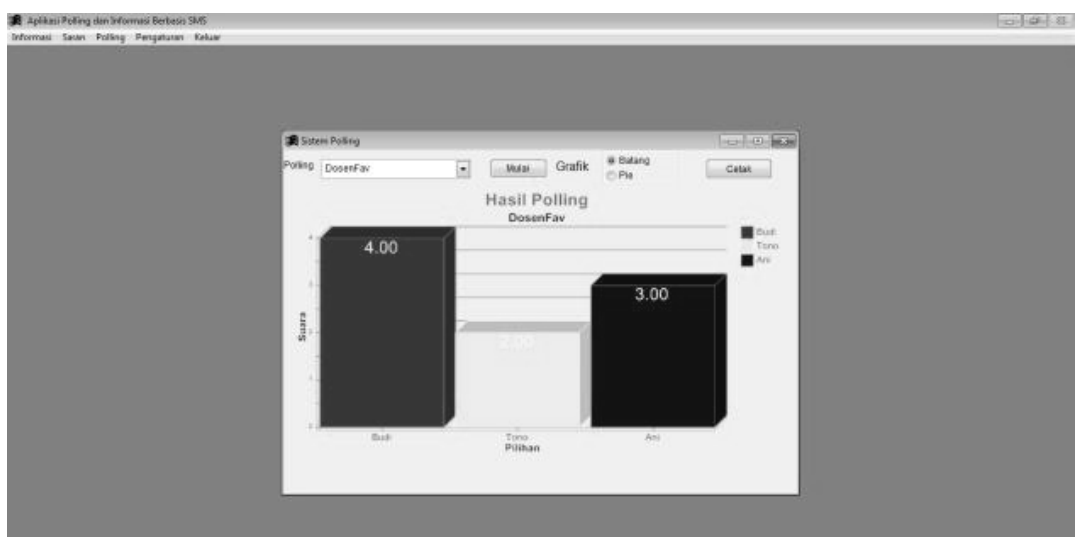

Gambar 4.3 Antarmuka form polling

\section{Penutup}

\subsection{Kesimpulan}

Berdasarkan dari rancangan dan implementasi yang dilakukan dapat diambil kesimpulan sebagai berikut:

1. Aplikasi Polling dan Informasi Berbasis SMS merupakan aplikasi yang menempatkan admin sebagai pengatur utama jalannya aplikasi ini dimana anggota hanya berperan dalam partisipasinya untuk menanyakan informasi dan memberikan pendapatnya dalam polling yang dijalankan.

2. Aplikasi ini merupakan sistem tunggal yang berjalan dalam satu perangkat.

3. Aplikasi ini berfungsi sebagai pusat informasi melalui SMS di mana melalui SMS kepada anggota organisasi yang menggunakan aplikasi ini. Sebaliknya anggota juga dapat menanyakan suatu informasi melalui SMS.

4. Aplikasi ini juga berfungsi sebagai pengumpul polling melalui SMS yang dihimpun dari anggota organisasi atau secara bebas.

5. Aplikasi ini dirancang untuk mendukung jalannya penginformasian dan polling secara umum yang mana penyesuaian data dapat dilakukan secara mandiri oleh pengguna aplikasi. 


\subsection{Saran}

Berdasar penelitian dan hasil pengembangan aplikasi yang dilakukan dapat disimpulkan bahwa Aplikasi Polling dan SMS ini membutuhkan pengembangan dari sektor keamanan, kemampuan mengirim dan mengelola SMS serta perbaikan antarmuka.

\section{DAFTAR PUSTAKA}

Bazian, Menachem, dkk. Using Visual Foxpro 6. Indianapolis. USA: Macmillan Computer Publishing.

Cannolly, Thomas M., Carolyn Begg. 2004. Database Systems: A Practical Approach to Design, Implementation, and Management. Essex, England: Pearson Education Limited.

Ciha`r, Michal. 2011. Gammu Manual. Wammu.eu.

Eriyanto. 1999. Metodologi Polling: Memberdayakan Suara Rakyat. Bandung: Remaja Rosda Karya.

Fathansyah. 1999. Basis Data. Bandung: CV. Informatika

Hartono, Jogianto. 1998. Analisis dan Desain Sistem Informasi: Pendekatan Tersturktur Teori dan Praktek Aplikasi Bisnis. Yogyakarta: Andi.

Hoffer, Jeffrey A., Mary B. Prescott, Fred R. McFadden. 2002. Instructor's Manual, Modern Database Management. Pearson Prentice Hall

Le Vie, Jr., Donald. Understanding Data Flow Diagrams. Texas: Integrated Concepts, Inc.

Loudon, Kenneth C., Jane P. Loudon. 2015. Management Information Systems: Managing The Digital Firm. : Pearson Education

Maulana, Sofyan. 2015. 5 Proyek Populer SMS Gateway. Jakarta: PT Elex Media Komputindo.

Munif, Abdul. 2013. Basis Data. Jakarta: Kementerian Pendidikan \& Kebudayaan, Direktorat Jenderal Peningkatan Mutu Pendidikan \& Tenaga Kependidikan.

Rosenfeld, Louis, Peter Morville \& Jorge Arongo. 2015. Information Architectur for The Web and Beyond. Canada: O'Reilly Media, Inc.

Solichin, Achmad. 2010. MySQL Dari Pemula Hingga Mahir. Jakarta: Unversitas Budi Luhur.

Stair, Ralph M., Reynolds, George. 2011. Principles of Information Systems, A Managerial Approach. Boston, USA: Course Technology Cengage Learning.

Sudrajat, Dadang. 2012. Cara Mudah Menyusun Program Aplikasi dengan Microsoft Visual Foxpro. Jakarta: D@TAKOM Lintas Buana.

Sunardi, dkk. 2009. Aplikasi SMS Gateway. Jurnal Teknologi Informasi DINAMIK Volume XIV, No.1, Januari 2009: 30-34

Widyaningtyas, Arinta. Sistem Informasi Akademik Berbasis SMS Gateway Menggunakan Metode Prototype. Semarang: Universitas Dian Nuswantoro.

Yourdon, Erdward. 2006. Just Enough Structured Analysis. Yourdon.com.

Yulianto, Ardhian Agung, dkk. 2009. Analisis dan Desain Sistem Informasi. Bandung: Politeknik Telkom Bandung.

Zwass, Vladimir. 1998. Foundations of Information System. Singapore: McGraw-Hill Companies Inc 